\title{
Morphological Features in Children with Autism Spectrum Disorders: A Matched Case-Control Study
}

\author{
Heval Ozgen • Gerhard S. Hellemann • Rebecca K. Stellato • Bertine Lahuis • \\ Emma van Daalen - Wouter G. Staal • Marije Rozendal • Raoul C. Hennekam • \\ Frits A. Beemer $\cdot$ Herman van Engeland
}

Published online: 15 May 2010

(C) The Author(s) 2010. This article is published with open access at Springerlink.com

\begin{abstract}
This study was designed to examine morphological features in a large group of children with autism spectrum disorder versus normal controls. Amongst 421 patients and 1,007 controls, 224 matched pairs were created. Prevalence rates and odds ratios were analyzed by conditional regression analysis, McNemar test or paired $t$-test matched pairs. Morphological abnormalities were significantly more prevalent in patients with autism than in the normal control group and 48 morphological features distinguished patients from controls. Our findings show that morphological features are associated with autism. Exploring potential underlying genetic mechanisms of this association might lead to a better understanding of autism.
\end{abstract}

Electronic supplementary material The online version of this article (doi:10.1007/s10803-010-1018-7) contains supplementary material, which is available to authorized users.

H. Ozgen - B. Lahuis · E. van Daalen ·

W. G. Staal · M. Rozendal · H. van Engeland

Department of Child and Adolescent Psychiatry,

University Medical Center, Utrecht, The Netherlands

H. Ozgen · B. Lahuis - E. van Daalen ·

W. G. Staal · M. Rozendal · H. van Engeland

Rudolf Magnus Institute of Neuroscience,

University Medical Center, Utrecht, The Netherlands

G. S. Hellemann

Center for Biostatistics, Utrecht University,

Utrecht, The Netherlands

R. K. Stellato

SIStat, Semel Institute for Neuroscience,

University of California, Los Angeles, CA, USA

R. C. Hennekam

Department of Pediatrics, Emma Children's Hospital,

Academic Medical Center, Amsterdam, The Netherlands
Keywords Minor anomalies - Common variants . Dysmorphology · Heterogeneity · Etiology · Biological marker

\section{Introduction}

Autism Spectrum Disorder (ASD) is a neurodevelopmental disorder characterized by qualitative impairments in social interaction and communication skills, accompanied by repetitive and stereotyped behaviors and interests (APA 2000). Family and twin studies have shown that the risk for autism is largely determined by genetic factors $(>90 \%)$ (Geschwind and Levitt 2007). However, the pattern of inheritance is not straightforward and may include additive effects of common risk alleles, rare gene mutations (e.g., fragile-X) chromosomal abnormalities (e.g., copy

R. C. Hennekam

Clinical and Molecular Genetics Unit, Institute of Child Health, UCL, London, UK

\section{F. A. Beemer}

Department of Medical Genetics, University Medical Center, Utrecht, The Netherlands

H. Ozgen ( $\square)$

Department of Child and Adolescent Psychiatry, Rudolf Magnus Institute of Neuroscience, UMC Utrecht, HP B01.201, PO Box 85500, 3508 GA Utrecht, The Netherlands

e-mail: h.m.ozgen@umcutrecht.nl 
number variants or CNVs), and possibly environmental insults (Mendelsohn and Schaefer 2008). Despite the significant heritability, finding the cause has been daunting due to genetic complexity and phenotypic variation (Szatmari et al. 2007; Abrahams and Geschwind 2008). Such heterogeneity in autism has led researchers to seek for reliable diagnostic tools to create genetically homogenous subgroups.

The study of head circumference and other morphological characteristics has begun to merge into autism research to stratify ASDs into more homogenous subgroups. Excessive head growth found in the first year of life, in children later diagnosed with autism, has been one of the most promising quantitative traits (Miles et al. 2000; Sacco et al. 2007). With respect to other morphological characteristics, an excess of minor physical anomalies (MPAs) in autistic individuals received specific attention (Ozgen et al. 2010). Although in the psychiatric literature the term "MPAs" is generally accepted, morphological features encompass major abnormalities as well as minor variants (Aase 1990; Merks et al. 2008). Minor variants are defined as slight morphological deviations that have no serious medical or cosmetic significance, however, they are of great value to the clinician because (1) they can be utilized as indicators of underlying disease susceptibility or markers of disturbed development (e.g., they are found to be more common in individuals with an obvious major embryonic defect; Aase 1990; McGrath et al. 2002); (2) They serve as external indicators of neurodevelopment because of the close relationship between cerebral and craniofacial development (Hammond et al. 2008); (3) Topography of morphological features could provide clues to the process of ASDs as they reflect adverse events during critical periods of development, usually within the first and second trimester (Lane et al. 1997). Minor variants that are observed in $4 \%$ or less of the normal population are termed minor anomalies, and those occurring in more than $4 \%$ of the normal population are termed common variants.

There is now robust evidence for the association between morphological abnormalities and autism (Ozgen et al. 2010). Existing studies, however, are limited by a number of methodological constrains: a. lack of standardization of the nomenclature and the absence of uniform diagnostic criteria; b. patients with different ethnic backgrounds were included; c. patients were not physically examined by the investigators specifically for the study; d. lack of control data or use of biased populations (e.g., hospital-based cohorts); e. relatively small sample sizes; f. no reports on interrater reliability; g. lack of consideration on gender effect. Moreover, the majority of studies that have assessed the incidence of morphological abnormalities in autism used the Waldrop scale (vide infra), with occasional modifications and omissions of items (Waldrop et al. 1968; Ismail et al. 1998). While the Waldrop scale is able to distinguish patients from controls, it has been criticized for inherent limitations regarding content and form; i.e., its restricted range of 18 items and low sensitivity (Lane et al. 1997).

With these caveats in mind, here we present an approach to study morphological features in a large sample of children with autism and a matched-case control group by using detailed definitions of the phenotype and an internationally accepted classifying list of 683 morphological features (Merks et al. 2003).

\section{Method}

\section{Participants}

We examined all consecutive patients attending the Department of Child and Adolescent Psychiatry (CAP) of the University Medical Center in Utrecht, the Netherlands. This hospital provides health services to a wide range of patients from mainly the centre and south of the Netherlands. During the study period, patients and/or their caregivers were invited in writing to participate both to psychological assessments as to a physical examination. The participants in the ASD group were included only if they had a documented diagnosis of an autistic spectrum disorder (autistic disorder, Asperger's disorder or PDDNOS). Consensus diagnoses were made for each case, consisting of a developmental history, medical examination, and a structured DSM-IV psychiatric interview by experienced child psychiatrists and confirmed by using ADI-R (Lord et al. 1994). Children with any known syndrome or with mental retardation (ICD-9 codes 317-319; IQ < 70; Smith and Bostian 1964; Rodier et al. 1997) were excluded. Ethnicity was registered because it can influence the external phenotype (McGrath et al. 2002; Merks et al. 2008). 1,007 controls were examined and analyzed in an identical way. Controls were recruited from the city of Haarlem and the surrounding semirural and rural area, because the region was found to be an excellent representative of the general health profile in the Netherlands (Cluitmans et al. 2002; Van Lier 2004; Merks et al. 2006).

The study procedures were approved at the medical ethics committee (METC) of the University Medical Center, Utrecht, the Netherlands. Patients and controls entered the study only after written informed consent was obtained from themselves and/or their parents. 
Terminology and Classification of Morphological Characteristics

A hierarchical tree was built, comprising 29 major anatomical areas, subdivided into 98 different structures, and containing 683 standardized morphological abnormalities. The morphological abnormalities were classified according to their (presumed) pathogenesis, and subdivided into (a) Major abnormalities, caused by abnormal development; and (b) Minor variants. The minor variants can be subdivided into two categories, based on their prevalence in the normal population: Minor anomalies, having a prevalence in the normal population by definition of $\leq 4 \%$; and Common variants, having by definition a prevalence in the normal population of $>4 \%$ (Supp. Fig. 1; Aase 1990; Merks et al. 2003).

Morphological Examination (Qualitative and Quantitative measures)

All patients and controls were carefully examined in an identical way by the same trained examiner (HMO). The clinical examination consisted of standard morphological measurements and comprised a broad range of qualitative and quantitative physical measurements. All items in the Waldrop-scale were included in this list and a clear differentiation between major abnormalities, minor anomalies and common variants were introduced. It should be emphasized that the distinction between major and minor anomalies is pragmatic, and only defined by the effect on the child. Techniques and standards of measurement were adapted from the studies by Aase (1990) and Hall and Hall (2007). Height, weight, head circumference, inner and outer canthal distance, ear length, hand length and palm length were measured and shoe size was converted into foot length. The location of some of these quantitative measurements is displayed in Supp. Fig. 2. No specific equipment other than a ruler and measuring tape was used. Auscultation of the heart, abdominal palpation, examination of internal organs and of the external genitalia was not performed. Body mass index (BMI) is formulated as weight $(\mathrm{kg}) /$ height $(\mathrm{m})^{2}$ and interpreted with the reference of Van Buuren (2004). Palpebral fissure length (PFL) is defined as the distance between the inner and outer canthus of one eye (Hall and Hall 2007).

Reliability studies were conducted using a second observer (FAB, clinical geneticist/pediatrician) who examined 30 patients (9\%) of the ASD group, blind to the patients' diagnosis and to the results of morphological assessment of the first examiner. This resulted in a kappa score of 0.81 (Cohen 1960). For the controls, 111 children $(11 \%)$ were examined by a second observer $(\mathrm{RCH})$ resulting in a kappa score of 0.85 . Assessors were blinded to family status and to any previous diagnosis at the time of the assessment.

\section{Data Analysis}

To better determine whether patients with ASD had higher prevalence of dysmorphology we compared each of the quantitative and qualitative items in carefully selected matched pairs. To reduce the influence of ethnic variability in the matched pairs, analyses were restricted to Caucasian patients and controls. We used procedures in SPSS to match as many patients with autism as possible to controls based on sex and age ( \pm 2 years). When more than one control was available for matching to a case, the final match was randomly selected from the pool. Patients with no matching comparison subject were excluded from the analysis.

For the analysis, a binary variable was created for each anomaly such that the presence of an anomaly was scored qualitatively as present " 1 " or absent " 0 ".

Paired $t$-tests were used to examine differences in morphological features between autistics and controls for continuous variables, McNemar's tests for dichotomous variables and conditional logistic regression for categorical variables. Exact $p$ values from the McNemar's test were used to compare controls and patients on these variables. Inflated alpha levels due to multiple testing were addressed by using the Holm-Bonferroni approach to adjust $p$-values. Statistical significance was set at $p<.05$ (2-tailed) for all analyses (Holm 1979). Matching and data analysis were performed using the Statistical Package for the Social Sciences (SPSS release 15, SPSS Inc., Chicago, IL).

\section{Results}

\section{Demographics}

The development of the sample for the present study is summarized in a flowchart (Supp. Fig. 3)

A total of 442 consecutive patients were invited to participate; of these, 421 agreed to undergo extensive morphological assessments (95.2\%). The mean age at examination of the patients was 9.7 years (range 3-18 years), compared with 10.4 years (range 8-14 years) for controls. The male/ female ratio was 4.19 in patients and 0.93 in controls. Because of the large age and gender differences between autistics and controls, analyses were performed on matched pairs. There were no significant group differences between case and controls with regard to their socioeconomic background. Supp. Table 1 shows the baseline characteristics for the entire sample and the matched sample. Among 421 cases, 32 subjects were excluded from the analysis as being 
non-Caucasian, 31 were excluded as not fulfilling ASD criteria. Further, 28 children were excluded from the autistic group due to a diagnosis of a known syndrome or chromosomal abnormality (Supp. Table 2).

After matching on age and gender, 224 patients with autism and 224 controls were available for analysis. Of the 224 matched pairs, 186 (83\%) were male, and 38 (17\%) were female. The mean (SD) age of patients was $10.6(2.5)$ years and the mean age of controls was 10.6 (1.4) years.

\section{Quantitative Measurements}

The matched pairs were compared on height, weight, occipitofrontal circumference (OFC), inner canthal distance (ICD), and outer canthal distance (OCD). The mean differences between the measured anthropometry are given in Table 1. Measurement of BMI, weight, OFC, ICD, and OCD appears to be significantly higher in children with autism than in controls. However, when we stratified the data by gender, differences in BMI and OFC were only statistically significant in male children. Both male and female patients had statistically significant larger ICD and OCD than controls.

Table 1 shows the mean quantitative measurements for the total matched sample ( $N=448$ individuals), the female matched $(n=76)$, and the male matched sample $(n=372)$. There was a significant difference in OFC, ICD, and OCD. The mean OFC, ICD, OCD in children with ASD were significantly larger than the mean in controls $p<0.01$. ICD and OCD difference remained significant after controlling for OFC. Furthermore, height and weight was calculated as covariates to take the potential effects of general differences in body size into account and to establish the specificity of the OFC effect. Differences in OFC between the autistic and the control group were still significant after controlling for height and weight $(p<.05)$, suggesting that the observed differences in OFC were not due to a generalized enlargement in body size. No differences between autistics and controls were found for height, middle finger length, hand palm length, hand length and foot length.

Occurrence of Morphological Abnormalities in Patients with ASD

Major abnormalities, minor anomalies and common variants were significantly more prevalent in the patients with ASD, and patients with ASD had a significantly higher occurrence of combinations of major abnormalities, minor anomalies and common variants (Fig. 1). One or more major abnormalities were present in $43.8 \%$ of patients (12.5\% in controls, $p<.001$ ), two or more abnormalities in $12.1 \%$ of patients $(0.9 \%$ in controls, $p<.001)$, and three or more abnormalities were found in $3.6 \%$ compared with none in controls $(p<.001$; Fig. 1$)$. One or more minor anomalies were found in $98.2 \%$ of patients $(58.9 \%$ in controls, $p<.001$ ), two or more minor anomalies in $89.7 \%$ of patients $(25.0 \%$ in controls, $(p<.001)$, and three or

Table 1 Quantitative measurements of the body features (paired sample $t$-test)

\begin{tabular}{|c|c|c|c|c|c|c|}
\hline & \multicolumn{2}{|c|}{$\begin{array}{l}\text { Boys only (186 pairs, matched } \\
\text { by age) }\end{array}$} & \multicolumn{2}{|c|}{$\begin{array}{l}\text { Girls only ( } 38 \text { pairs, matched } \\
\text { by age) }\end{array}$} & \multicolumn{2}{|c|}{$\begin{array}{l}\text { Matched sample (total; matched } \\
\text { by sex and age) }\end{array}$} \\
\hline & $\begin{array}{l}\text { Mean difference (SE) } \\
\text { (control-case) }\end{array}$ & $t$ & $\begin{array}{l}\text { Mean difference (SE) } \\
\text { (control-case) }\end{array}$ & $t$ & $\begin{array}{l}\text { Mean difference (SE) } \\
\text { (control-case) }\end{array}$ & $t$ \\
\hline Height $(\mathrm{cm})$ & $-1.9(1.1)$ & -1.7 & $-1.0(2.4)$ & -0.4 & $-1.7(1.0)$ & -1.7 \\
\hline Weight (kg) & $-4.9(1.0)$ & $-4.5^{*}$ & $-3.5(2.6)$ & -1.3 & $-4.7(1.0)$ & $-4.7 *$ \\
\hline BMI $\left(\mathrm{kg} / \mathrm{m}^{2}\right)$ & $-1.2(0.2)$ & $-4.3^{*}$ & $-1.0(0.7)$ & -1.3 & $-1.1(0.2)$ & $-4.4^{*}$ \\
\hline $\mathrm{OFC}(\mathrm{cm})^{\wedge}$ & $-0.5(0.1)$ & $-2.9^{*}$ & $-0.2(0.4)$ & -0.5 & $-0.4(0.1)$ & $-2.9 *$ \\
\hline $\mathrm{ICD}(\mathrm{cm}) \#$ & $-0.1(0.0)$ & $-3.7 *$ & $-0.2(0.0)$ & $-2.6^{*}$ & $-0.1(0.0)$ & $-4.3^{*}$ \\
\hline OCD $(\mathrm{cm}) \#$ & $-0.8(0.0)$ & $-9.4^{*}$ & $-0.7(0.1)$ & $-4.7 *$ & $-0.8(0.0)$ & $-10.3^{*}$ \\
\hline PFL (cm)\# & $-0.3(0.0)$ & $-9.1^{*}$ & $-0.2(0.0)$ & $-3.6^{*}$ & $-0.3(0.0)$ & $-9.7 *$ \\
\hline $\begin{array}{l}\text { Middle finger length } \\
(\mathrm{cm})\end{array}$ & $-0.0(0.0)$ & -1.7 & $0.0(0.1)$ & 0.0 & $-0.1(0.0)$ & -1.6 \\
\hline Handpalm length (cm) & $-0.0(0.0)$ & -1.0 & $0.1(0.1)$ & 0.7 & $-0.0(0.0)$ & -0.6 \\
\hline Hand length $(\mathrm{cm})$ & $-0.2(0.1)$ & -1.6 & $0.1(0.2)$ & 0.4 & $-0.1(0.1)$ & -1.3 \\
\hline Foot length $\mathrm{cm}$ ) & $-0.1(0.1)$ & -0.4 & $0.7(0.4)$ & 1.5 & $0.0(0.1)$ & 0.2 \\
\hline
\end{tabular}

OFC occipito frontal; $B M I$ body mass index; ICD inner Canthal; $O C D$ outer Canthal; $P F L$ palpebral fissure

* statistically significant at $p<0.05$

\# controlling for OFC did not change the results

$\wedge$ controlling for weight, height, ICD and OCD did not changes the results 
Fig. 1 Prevalence of major abnormalities, minor anomalies and common variants in the matched sample of autistics versus controls
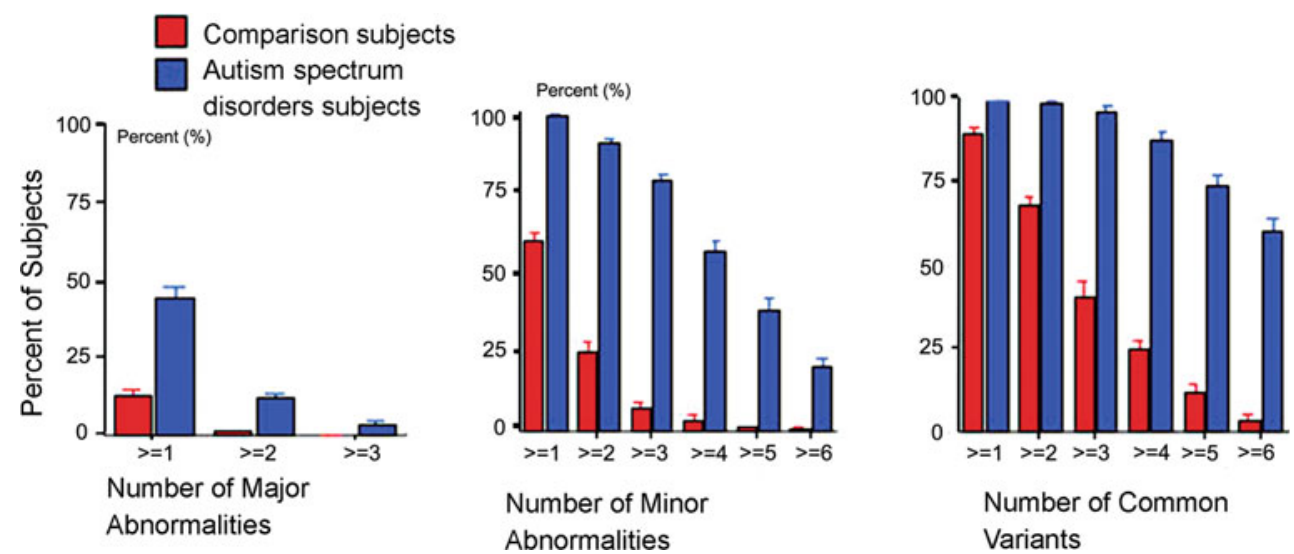

more minor anomalies were found in $77.7 \%$ of patients compared with $7.1 \%$ in controls $(p<.001$; Fig. 1$)$. One or more common variants were found in $100 \%$ of patients (89.3\% in controls, $p<.001)$, two or more minor anomalies in $98.2 \%$ of patients $(67.4 \%$ in controls, $(p<.001)$, and three or more minor anomalies were found in $95.5 \%$ of patients compared with $41.1 \%$ in controls $(p<.001$; Fig. 1).

Furthermore, in a univariate analysis, 63 of the 683 morphological features were found to occur significantly $(p<.001)$ more often in patients compared with controls. After correction for multiple testing, 48 morphological abnormalities were significantly ( $p<.05$, two-tailed) more common among patients than controls. The odds ratios (OR's) for the occurrence of these anomalies are shown in Table 2. Thirty-nine of the morphological features were also significantly more common in male matched pairs, and in two of these, the difference was also significantly more frequent in female matched pairs.

\section{Discussion}

We have demonstrated a strikingly high prevalence of morphological abnormalities in a large cohort of patients with ASD without mental retardation, compared with controls. The results support existing research findings from a meta-analysis by Ozgen et al. (2010), as well as those of previous reports in the literature (Steg and Rapoport 1975; Walker 1977; Campbell et al. 1978; Gualtieri et al. 1982; Rodier et al. 1997; Hardan et al. 2006; Miles et al. 2008). In this present study, we tried to overcome the methodological limitations that occurred in previous studies. The main strengths of our study are careful clinical assessments using stringent morphological characterization, robust statistical methods and adequate power relative to previous studies. This sample size of 224 matched patient-control pairs is the largest to be studied to date for morphological features in ASD. Furthermore, in the present study all patients underwent a clinical morphological examination, using a list of 683 well-defined morphological abnormalities, assessed by the same investigator, and co-assessed blindly by a second investigator in about $10 \%$.

Several interesting findings emerged from this study. First, our study demonstrated that the frequency of morphological anomalies is highly elevated in ASD without mental retardation, that not only minor anomalies but also major abnormalities and common variants are significantly more prevalent in children with autism versus controls. Some of the features may be direct malformations whereas others might be indirect e.g., open mouth expression, dry skin, pes planus. This finding resembles that of an association of autism with $\mathrm{CNVs}$, which are common under normal circumstances, but also are an important aspect of genomic disorders, i.e., diseases caused by an alteration of the genome causing complete loss of copy, gain of copy or disruption of a dosage-sensitive gene (Sebat et al. 2007). In fact, Engels et al. (2007) showed a direct association between the severity of physical anomalies and the gene content of the microdeletions/microduplications.

Second, males with autism showed a trend for more morphological abnormalities scored than females, i.e., males with ASD without mental retardation were notably having significantly more morphological abnormalities than female patients. Although one has to be cautious in interpreting these gender differences because of large differences in sample size, there are many plausible explanations for the observed differences. An explanation might be that the human male brain is generally more vulnerable to endogenous or exogenous factors which are poorly understood (Mizuno 2000). In addition, sex differences in brain structure and development are well known (BaronCohen et al. 2005). These results may also substantiate that some genetic risk factors influencing liability to autism in males and females might act differently. Furthermore, in schizophrenia literature there are findings parallel to ours 
Table 2 Morphological features occurring significantly more frequent in children with autism versus controls

\begin{tabular}{|c|c|c|c|c|c|}
\hline Morphological feature & $\begin{array}{l}\text { Controls } \\
(n=224)\end{array}$ & $\begin{array}{l}\text { Autism } \\
(n=224)\end{array}$ & OR $(95 \% \mathrm{CI})$ & $p$ & Type of abnormality \\
\hline$\S$ Brachycephaly & 0 & 18 & $\infty(1.5-\infty)$ & 0.001 & Minor anomaly \\
\hline$\S \#$ Face asymmetry & 4 & 113 & $27.6(19.3-73.9)$ & $<0.001$ & Minor anomaly \\
\hline$\S$ Face coarse & 2 & 27 & $12.9(3.2-52.5)$ & $<0.001$ & Minor anomaly \\
\hline$\S$ Forehead prominent & 6 & 53 & $8.2(3.5-19)$ & $<0.001$ & Minor anomaly \\
\hline$\S$ Eyes assymetry & 0 & 15 & $13.7(2-95.1)$ & 0.001 & Minor anomaly \\
\hline$\S$ Eyes deeply set & 9 & 42 & $6.4(2.7-15)$ & $<0.001$ & Minor anomaly \\
\hline §Prominent premaxilla & 4 & 30 & $7.3(2.6-20.6)$ & 0.001 & Minor anomaly \\
\hline$\S$ Mounth asymmetry & 0 & 23 & $\infty(2.3-\infty)$ & $<0.001$ & Minor anomaly \\
\hline Macrostomia & 0 & 14 & $\infty(0.9-\infty)$ & $<0.001$ & Minor anomaly \\
\hline Microstomia & 2 & 15 & $14(1.8-106)$ & 0.022 & Minor anomaly \\
\hline$\S$ Short philtrum & 5 & 35 & $6.9(2.7-17.4)$ & $<0.001$ & Minor anomaly \\
\hline Upper lip cupid bow & 5 & 25 & $5.9(2.1-16.7)$ & 0.032 & Minor anomaly \\
\hline §\#Palate high/narrow & 17 & 83 & $5.7(3.2-10)$ & $<0.001$ & Minor anomaly \\
\hline §Long uvula & 3 & 23 & $7.5(2.3-24.4)$ & & Minor anomaly \\
\hline $\begin{array}{l}\text { §Macrodontia/teeth asymmetry/ } \\
\text { abnormally shaped teeth }\end{array}$ & 3 & 33 & $7.8(2.8-21.8)$ & $<0.001$ & Minor anomaly \\
\hline$\S$ Ear low-set & 1 & 20 & $18.3(2.7-124)$ & 0.004 & Minor anomaly \\
\hline$\S$ Ear posteriorly rotated & 5 & 33 & $10(3.1-32.2)$ & $<0.001$ & Minor anomaly \\
\hline Ear lobe crease & 0 & 12 & $\infty(0.6-\infty)$ & 0.035 & Minor anomaly \\
\hline §Toes syndactyly & 2 & 61 & $13.9(3.4-56.2)$ & $<0.001$ & Minor anomaly \\
\hline §Halluces valgus & 4 & 29 & $9.1(2.8-29.3)$ & $<0.001$ & Minor anomaly \\
\hline$\S$ Hypermobile/hyperlax joints & 21 & 74 & $5.4(2.9-9.9)$ & $<0.001$ & Minor anomaly \\
\hline Multiple nevi & 9 & 28 & $3.2(1.5-6.8)$ & 0.031 & Minor anomaly \\
\hline Hypo-/depigmentation patches & 4 & 18 & $5.5(1.6-18.5)$ & 0.033 & Minor anomaly \\
\hline$\S$ Face expression less/dull & 0 & 15 & $\infty(1-\infty)$ & 0.001 & Major abnormality \\
\hline §Open mouth appearance & 0 & 18 & $\infty(1.5-\infty)$ & $<0.001$ & Major abnormality \\
\hline$\S,{ }^{\mathrm{a}}$ Abnormal whorl (non-frontal) & 0 & 87 & $\infty(8.4-\infty)$ & $<0.001$ & Common variant \\
\hline$\S$ Full cheeks & 5 & 31 & $9.3(2.9-30)$ & $<0.001$ & Common variant \\
\hline$\S$ Periorbital fullness & 8 & 49 & $7.7(3.3-17.9)$ & $<0.001$ & Common variant \\
\hline$\S$ Eyebrows arched & 1 & 37 & $33.7(5-\infty)$ & $<0.001$ & Common variant \\
\hline$\S$ Large nose & 4 & 29 & $7(2.5-19.9)$ & 0.002 & Common variant \\
\hline$\S$ Nose bridge prominent & 28 & 66 & $3.5(1.9-6.2)$ & $<0.001$ & Common variant \\
\hline$\S$ Nose concave & 4 & 27 & $6.6(2.3-18.6)$ & 0.006 & Common variant \\
\hline Lower lip full & 31 & 65 & $2.6(1.6-4,4)$ & 0.001 & Common variant \\
\hline$\S$ Upper lip thin & 21 & 60 & $3.4(1.9-5.9)$ & $<0.001$ & Common variant \\
\hline$\S$ Prominent philtrum & 5 & 30 & $5.9(2.3-15)$ & 0.004 & Common variant \\
\hline$\S$ Lower jaw prominent & 0 & 31 & $\infty(0.6-\infty)$ & $<0.001$ & Common variant \\
\hline$\S$ Dimpled/grooved chin & 1 & 27 & $\infty(0.5-\infty)$ & $<0.001$ & Common variant \\
\hline$\S$ Prominent ear & 8 & 40 & $5.5(2.4-12.2)$ & $<0.001$ & Common variant \\
\hline$\S^{, a}$ Ear lobes attached & 25 & 78 & $4(2.4-6.9)$ & $<0.001$ & Common variant \\
\hline §Clinodactyly (fingers) & 11 & 40 & $3.6(1.8-7)$ & 0.001 & Common variant \\
\hline §Clinodactyly (toes) & 9 & 48 & $5.8(2.7-12.2)$ & $<0.001$ & Common variant \\
\hline Inverted nipples & 6 & 28 & $4.6(1.9-11)$ & 0.035 & Common variant \\
\hline Toes widely spaced & 1 & 22 & $20(2.9-\infty)$ & 0.001 & Common variant \\
\hline 2 nd toe longer than $1 \mathrm{st}$ & 9 & 33 & $4.3(1.9-9.8)$ & 0.021 & Common variant \\
\hline$\S$ Pes planus & 4 & 36 & $8.8(3.1-24.4)$ & $<0.001$ & Common variant \\
\hline$\S^{\text {,a }}$ Sandal gap (toes) & 57 & 144 & $4.4(2.8-6.8)$ & $<0.001$ & Common variant \\
\hline$\S$ Dry skin & 12 & 60 & $6.9(3.3-14.4)$ & $<0.001$ & Common variant \\
\hline
\end{tabular}


Table 2 continued

\begin{tabular}{llllll}
\hline Morphological feature & $\begin{array}{l}\text { Controls } \\
(n=224)\end{array}$ & $\begin{array}{l}\text { Autism } \\
(n=224)\end{array}$ & OR (95\% CI) & $p$ & Type of abnormality \\
\hline §Nails striped & 1 & 41 & $37.3(5.6-\infty)$ & $<0.001$ & Common variant \\
\hline
\end{tabular}

${ }^{a}$ MPA in Waldrop scale \# Significant in girls $(p<0.05) \S$ Significant in boys $(p<0.05)$ Forty-eight morphological features occurring significant more frequently in patients with autism compared to controls in univariate analysis (McNemar's test $p<0.05$; Holm-Bonferroni corrected)

regarding a gender effect on the occurrence of morphological characteristics (McGrath et al. 1995; Akabaliev and Sivkov 2007).

Third, the pattern of changes in morphological features was not straightforward. For example, we found that both smaller and larger mouth size were significantly elevated in patients with ASD compared to controls. Moreover, in contrast to some previous studies (Hardan et al. 2006; Rodier et al. 1997), we did not find that the presently studied patients with ASD had smaller ICD. On the contrary, we found that our patients had larger ICD and OCD, a finding that is consistent with the findings of Walker (1977) and Bailey et al. (1995). This observation may suggest either that the direction of changes in the orbital distance may be a random outcome of a common neurodevelopmental defect or that these opposite effects may underlie separate neurodevelopmental defects which might eventually lead to a better characterization of subgroups of patients with autism.

Fourth, in a recent meta-analysis in schizophrenia, a higher prevalence of morphological abnormalities was also established (Weinberg et al. 2007) with similar overlapping markers (e.g., brachycephaly; McGrath et al. 2002). Indeed, there is strong indication that individuals with schizophrenia may display evidence of craniofacial dysmorphology. Some evidence for such an overlap comes from the observation that individuals with ASD may also be at greater risk for schizophrenia (Mouridsen et al. 2008).

There are certain limitations that should be borne in mind when interpreting the results. First, although our sample size provides the necessary statistical power for quantitative analyses, yet some categorical analyses may suffer from power limitations due to the relatively small number of females in the sample. Notably, our sample was predominantly male. The potential difference in morphological features found between males and females require further confirmation.

Second, as morphologic examination requires in-person examination, it is generally not possible for the raters to be blind to diagnosis. However, $11 \%$ of controls and $9 \%$ of patients were scored independently by two observers, resulting in high kappa scores. Additionally there were no prior hypotheses as of which morphological abnormalities should be associated with autism.
Third, we limited our study population to Caucasian patients and controls as ethnicity can influence the prevalence of morphological abnormalities. Future studies are needed to establish similar norms for other ethnic groups. Likewise, we restricted ourselves to non-mentally retarded ASD patients. Therefore, we cannot generalize our findings to mentally retarded ASD patients or patient subgroups.

Forth, it is typically quite a challenge to determine whether these features are risk factors. The possible causal relevance of the association between disturbed prenatal development and subsequent autism has stimulated considerable discussion. In the present consideration of causality, we do not suggest that abnormal morphology in itself causes autism. In addition, we acknowledge that there are many disorders with similar morphological characteristics. e.g., increased head size. The same feature has already been shown to be related to a particular SNP variant in people with autism (Conciatori et al. 2004) as well as in people without a diagnosis (Muscarella et al. 2007). On the other hand, people with a very different etiology for autism, in utero exposure to valproic acid, also exhibit increased head size (Rasalam et al. 2005). Further studies are needed to discover the specificity, sensitivity and predictive value of these features for ASD. Moreover, some of the morphological characteristics among families may not be related to the ASD; demonstrating a genetic component independent of any syndrome and condition. Therefore, we recommend sib comparisons as future studies.

Last, the goal of this analysis was to provide a detailed analysis for the association of morphological features and ASD without mental retardation. We have not been able to address other intriguing questions such as clustering of the morphological features in different subgroups of ASD. These associations probably exist but are beyond the scope of this study. While we did not intend to establish specificity of single phenotypic characteristics to specific subtypes of ASD, we consider it possible that sets of physical anomalies might be related to severity of illness, or those specific phenotypic behavioral characteristics may define even more subtypes of ASD.

The current findings may have implications for future research, psychiatric nosology and clinical practice. With regard to future research implications, our findings help to reconcile previous puzzling evidence about the relationship 
between morphological features and ASD such as the inconsistency of this association across topographical areas. With regard to psychiatric nosology, our study adds to a growing body of research that suggests that morphological features might identify subgroups of individuals with ASD. It is possible that a subgroup of individuals with a higher number of unusual morphological findings or specific combinations of morphological findings is at highest risk of developing ASD without mental retardation. With regard to implications for clinical practice, our results support the importance of measuring morphological features in individuals with ASD. We suggest that routine assessment of quantitative and qualitative measurements could provide clinicians with necessary information to homogenise the ASD. In turn, the early recognition of the risk associated with morphological abnormalities might help to address pressing needs for the care of individuals with ASD.

Acknowledgments The authors thank the patients, their parents and physicians for their participation in this study. We thank Dr. Gene McGuin for his excellent knowledge and help on the data management and matching analyses. We thank Dr. John McGrath for critically reading and helpful discussion of the manuscript.

Open Access This article is distributed under the terms of the Creative Commons Attribution Noncommercial License which permits any noncommercial use, distribution, and reproduction in any medium, provided the original author(s) and source are credited.

\section{References}

Aase, J. M. (1990). Diagnostic dysmorphology. New York: Plenum Medical Book Co.

Abrahams, B. S., \& Geschwind, D. H. (2008). Advances in autism genetics: On the threshold of a new neurobiology. Nature Reviews Genetics, 9(5), 341-355.

Akabaliev, V. H., \& Sivkov, S. T. (2007). Internal consistency of Waldrop physical anomaly scale in schizophrenic patients. Psychiatry Research, 150(1), 81-88.

American Psychiatric Association, American Psychiatric Association, \& Task Force on DSM-IV. (2000). Diagnostic and statistical manual of mental disorders: DSM-IV-TR (4th ed.). Washington, DC: American Psychiatric Association.

Bailey, A., Le Couteur, A., Gottesman, I., Bolton, P., Simonoff, E., Yuzda, E., et al. (1995). Autism as a strongly genetic disorder: Evidence from a British twin study. Psychological Medicine, 25(1), 63-77.

Baron-Cohen, S., Knickmeyer, R. C., \& Belmonte, M. K. (2005). Sex differences in the brain: implications for explaining autism. Science, 310(5749), 819-823.

Campbell, M., Geller, B., Small, A. M., Petti, T. A., \& Ferris, S. H. (1978). Minor physical anomalies in young psychotic children. American Journal of Psychiatry, 135(5), 573-575.

Cluitmans, T. L. M., Hooi, J. D., Nijbroek, W., \& Oosterlee, A. (2002). Gezondheidsprofiel Kennemerland; G.G.D. Kennemerland: Haarlem/Heemskerk.
Cohen, J. (1960). A coefficient of agreement for nominal scales. Educational and Psychological Measurement, 20, 37-46.

Conciatori, M., Stodgell, C. J., Hyman, S. L., O’Bara, M., Militerni, R., Bravaccio, C., et al. (2004). Association between the HOXA1 A218G polymorphism and increased head circumference in patients with autism. Biological Psychiatry, 55(4), 413-419.

Engels, H., Brockschmidt, A., Hoischen, A., Landwehr, C., Bosse, K., Walldorf, C., et al. (2007). DNA microarray analysis identifies candidate regions and genes in unexplained mental retardation. Neurology, 68(10), 743-750.

Geschwind, D. H., \& Levitt, P. (2007). Autism spectrum disorders: developmental disconnection syndromes. Current Opinion in Neurobiology, 17(1), 103-111.

Gualtieri, C. T., Adams, A., Shen, C. D., \& Loiselle, D. (1982). Minor physical anomalies in alcoholic and schizophrenic adults and hyperactive and autistic children. American Journal of Psychiatry, 139(5), 640-643.

Hall, J. G., \& Hall, J. G. (2007). Handbook of physical measurements (2nd ed.). Oxford; New York: Oxford University Press.

Hammond, P., Forster-Gibson, C., Chudley, A. E., Allanson, J. E., Hutton, T. J., Farrell, S. A., et al. (2008). Face-brain asymmetry in autism spectrum disorders. Molecular Psychiatry, 13(6), 614-623.

Hardan, A. Y., Keshavan, M. S., Sreedhar, S., Vemulapalli, M., \& Minshew, N. J. (2006). An MRI study of minor physical anomalies in autism. Journal of Autism and Developmental Disorders, 36(5), 607-611.

Holm, S. (1979). A simple sequentially rejective multiple test procedure. Scandinavian Journal of Statistics, 6, 65-70.

Ismail, B., Cantor-Graae, E., \& McNeil, T. F. (1998). Minor physical anomalies in schizophrenic patients and their siblings. American Journal of Psychiatry, 155(12), 1695-1702.

Lane, A., Kinsella, A., Murphy, P., Byrne, M., Keenan, J., Colgan, K., et al. (1997). The anthropometric assessment of dysmorphic features in schizophrenia as an index of its developmental origins. Psychological Medicine, 27(5), 1155-1164.

Lord, C., Rutter, M., \& Le Couteur, A. (1994). Autism diagnostic interview-revised: a revised version of a diagnostic interview for caregivers of individuals with possible pervasive developmental disorders. Journal of Autism and Developmental Disorders, 24(5), 659-685.

McGrath, J., El-Saadi, O., Grim, V., Cardy, S., Chapple, B., Chant, D., et al. (2002). Minor physical anomalies and quantitative measures of the head and face in patients with psychosis. Archives of General Psychiatry, 59(5), 458-464.

McGrath, J. J., van Os, J., Hoyos, C., Jones, P. B., Harvey, I., \& Murray, R. M. (1995). Minor physical anomalies in psychoses: associations with clinical and putative aetiological variables. Schizophrenia Research, 18(1), 9-20.

Mendelsohn, N. J., \& Schaefer, G. B. (2008). Genetic evaluation of autism. Seminars in Pediatric Neurology, 15(1), 27-31.

Merks, J. H., Ozgen, H. M., Cluitmans, T. L., van der Burg-van Rijn, J. M., Cobben, J. M., van Leeuwen, F. E., et al. (2006). Normal values for morphological abnormalities in school children. American Journal of Medical Genetics Part A, 140(19), 20912109.

Merks, J. H., Ozgen, H. M., Koster, J., Zwinderman, A. H., Caron, H. N., \& Hennekam, R. C. (2008). Prevalence and patterns of morphological abnormalities in patients with childhood cancer. JAMA, 299(1), 61-69.

Merks, J. H., van Karnebeek, C. D., Caron, H. N., \& Hennekam, R. C. (2003). Phenotypic abnormalities: terminology and classification. American Journal of Medical Genetics Part A, 123(3), 211-230.

Miles, J. H., Hadden, L. L., Takahashi, T. N., \& Hillman, R. E. (2000). Head circumference is an independent clinical finding associated with autism. American Journal of Medical Genetics, 95(4), 339-350. 
Miles, J. H., Takahashi, T. N., Hong, J., Munden, N., Flournoy, N., Braddock, S. R., et al. (2008). Development and validation of a measure of dysmorphology: Useful for autism subgroup classification. American Journal of Medical Genetics Part A, 146A(9), $1101-1116$.

Mizuno, R. (2000). The male/female ratio of fetal deaths and births in Japan. Lancet, 356(9231), 738-739.

Mouridsen, S. E., Rich, B., \& Isager, T. (2008). Psychiatric disorders in adults diagnosed as children with atypical autism: A case control study. Journal of Neural Transmission, 115(1), 135-138.

Muscarella, L. A., Guarnieri, V., Sacco, R., Militerni, R., Bravaccio, C., Trillo, S., et al. (2007). HOXA1 gene variants influence head growth rates in humans. American Journal of Medical Genetics Part B Neuropsychiatric Genetics, 144B(3), 388-390.

Ozgen, H. M., Hop, J. W., Hox, J. J., Beemer, F. A., \& van Engeland, H. (2010). Minor physical anomalies in autism: A meta-analysis. Molecular Psychiatry, 5(3), 300-307.

Rasalam, A. D., Hailey, H., Williams, J. H., Moore, S. J., Turnpenny, P. D., Lloyd, D. J., et al. (2005). Characteristics of fetal anticonvulsant syndrome associated autistic disorder. Developmental Medicine and Child Neurology, 47(8), 551-555.

Rodier, P. M., Bryson, S. E., \& Welch, J. P. (1997). Minor malformations and physical measurements in autism: Data from Nova Scotia. Teratology, 55(5), 319-325.

Sacco, R., Militerni, R., Frolli, A., Bravaccio, C., Gritti, A., Elia, M., et al. (2007). Clinical, morphological, and biochemical correlates of head circumference in autism. Biological Psychiatry, 62(9), $1038-1047$.

Sebat, J., Lakshmi, B., Malhotra, D., Troge, J., Lese-Martin, C., Walsh, T., et al. (2007). Strong association of de novo copy number mutations with autism. Science, 316(5823), 445-449.
Smith, D. W., \& Bostian, K. E. (1964). Congenital anomalies associated with idiopathic mental retardation. Journal of Pediatrics, 65, 189-196.

Steg, J. P., \& Rapoport, J. L. (1975). Minor physical anomalies in normal, neurotic, learning disabled, and severely disturbed children. Journal of Autism and Childhood Schizophrenia, 5(4), 299-307.

Szatmari, P., Paterson, A. D., Zwaigenbaum, L., Roberts, W., Brian, J., Liu, X. Q., et al. (2007). Mapping autism risk loci using genetic linkage and chromosomal rearrangements. Nature Genetics, 39(3), 319-328.

van Buuren, S. (2004). Body-mass index cut-off values for underweight in Dutch children. Ned Tijdschr Geneeskd, 148(40), 1967-1972.

van Lier, A. (2004). Sterfte in Noord-Holland en Flevoland. Analyse van sterftecijfers in de provincies Noord-Holland en Flevoland 1996-2002-regio Kennemerland. Haarlem: G.G.D. NoordHolland en Flevoland.

Waldrop, M. F., Pedersen, F. A., \& Bell, R. Q. (1968). Minor physical anomalies and behavior in preschool children. Child Development, 39(2), 391-400.

Walker, H. A. (1977). Incidence of minor physical anomaly in autism. Journal of Autism and Childhood Schizophrenia, 7(2), 165-176.

Weinberg, S. M., Jenkins, E. A., Marazita, M. L., \& Maher, B. S. (2007). Minor physical anomalies in schizophrenia: A metaanalysis. Schizophrenia Research, 89(1-3), 72-85. 